\title{
Primeras aproximaciones al estudio gráfico de la biblioteca patrimonial de la Orden de los Predicadores (Tunja, Colombia)
}

\author{
First approximations to the graphic study of the patrimony library of the Order of Preachers (Tunja, Colombia)
}

\author{
Claudia Angélica Reyes Sarmiento \\ Universidad Jorge Tadeo Lozano, Colombia \\ claudiaa.reyes@utadeo.edu.co \\ (iD https://orcid.org/0000-0001-6299-3624
}

\section{Resumen:}

Este artículo es producto de una investigación orientada al estudio gráfico e histórico del libro antiguo en Colombia, en la que se eligió la Colección de la Orden de los Predicadores, de la Biblioteca del Convento de Santo Domingo de Guzmán, de la ciudad de Tunja (Boyacá, Colombia), para describir y caracterizar los libros antiguos, en términos del diseño gráfico y editorial; investigación que está siendo desarrollada por el grupo de investigación: Estudios de la Imagen, de la Escuela de Diseño, Fotografía y Realización Audiovisuales, y el semillero en Teoría e Historia del Diseño Gráfico, adscritos a la Universidad Jorge Tadeo Lozano, de Bogotá. Este estudio corresponde a la primera fase de investigación, en la que se propusieron criterios y categorías del acervo del diseño gráfico para identificar y clasificar, como libros antiguos, el corpus que fue posible consolidar en la colección. Para ello, se recurrió a una serie de instrumentos que permitió recoger información relacionada con elementos materiales y de diseño del libro, Los resultados que se exponen en este artículo pretenden ser un aporte a la conservación y divulgación del patrimonio cultural de la Nación desde el área disciplinar del diseño gráfico y motivar el interés por el libro antiguo entre los profesionales e investigadores en este campo disciplinar, a través del análisis de la relación entre la estética, la cultura material y la producción gráfica, así como el conocimiento de la existencia e importancia de esta colección.

Palabras Clave: Libro antiguo, Historia del libro, Diseño gráfico, Patrimonio gráfico, Orden de Predicadores, Colombia.

\section{Abstract:}

This article is the product of an investigation oriented to the graphic and historical study of the ancient book in Colombia, in which the Collection of the Order of the Preacher by the Library of the Santo Domingo de Guzmán Convent, in the city of Tunja (Boyacá, Colombia) was chosen to describe and characterize old books, in terms of graphic and editorial design; The research that is being developed by the research group: Image Studies of the School of Design, Photography and Audiovisual Production, and the seedbed in Theory and History of Graphic Design, added to the Bogotá University, Jorge Tadeo Lozano. This study corresponds to the first phase of research, in which the criteria and categories from the collection of graphic design were proposed to identify and classify, as old books, the corpus that was possible to consolidate in the collection. To do this, a serie of instruments was used that allowed collecting information related to material and design elements of the book.

The results that are exposed in this article are intended to be a contribution to the conservation and dissemination of the cultural heritage of the Nation, from the disciplinary area of graphic design and motivate interest in the ancient book among professionals and researchers in this disciplinary field, through the analysis of the relationship between aesthetics, material culture and graphic production, as well as the knowledge of the existence and importance of this collection.

KEYWORDS: Antique book, History of the book, Graphic design, Graphic patrimony, Order of Preachers, Colombia.

\section{INTRODUCCIÓN}

Las comunidades religiosas de Colombia guardan y conservan con celo los libros que permitieron la circulación del conocimiento durante la Colonia. Son los que cumplieron la función de transmitir ideas de los centros culturales europeos a los habitantes del nuevo continente, tanto inmigrantes como americanos y que, como patrimonio bibliográfico del clero, se conserva en manos de la Iglesia. Tal es el caso de la Biblioteca del Convento de Santo Domingo de Guzmán, de Tunja (Boyacá), de la Orden de los Predicadores 
o Dominicana, que empezó a formarse en 1551 con la fundación de este claustro en la ciudad, dada la importancia de los libros en el proceso de evangelización de los indígenas y la educación de los criollos, con el que estaba comprometida esta orden:

A comienzos de 1537 partió de Santa Marta una expedición dirigida por Gonzalo Jiménez de Quesada rumbo al interior del Nuevo Reino de Granada, siguiendo el río Magdalena, hacia el sur. Tal expedición concluye con la fundación en 1538, de la ciudad de Santa Fe (o Santafé), la que sería desde entonces la capital del Nuevo Reino de Granada. A fines de 1540, llegaron al Altiplano por lo menos tres religiosos más procedentes de Santa Marta: Fr. Pedro Durán, Fr. Juan de Montemayor y Fr. Juan de Torres. El último marchó a Santafé, los dos primeros se quedaron en Tunja (Plata, 2016, p. 272).

Pedro Durán y Juan de Montemayor eran dominicos, quienes llegaron a Tunja un año después de fundación de la ciudad, en 1539. De Durán se afirma que bautizó a Aquimín, último zaque del territorio conocido como Hunza, y a Sugamuxi, máximo sacerdote de los muiscas (Plata, 2016, p. 16). En esta ciudad, "de acuerdo con los censos de 1551, los dominicos ya administraban activamente 36 centros doctrineros" (Rivadeneira como se cita en Universidad Santo Tomas [USTA], 2011, p. 46), y entre los siglos XVI y XVII llegaron a fundar 25 conventos en la Nueva Granada (ver imagen 1).

\section{FIGURA 1}

Mapa de distribución de los conventos dominicos en la Nueva Granada.

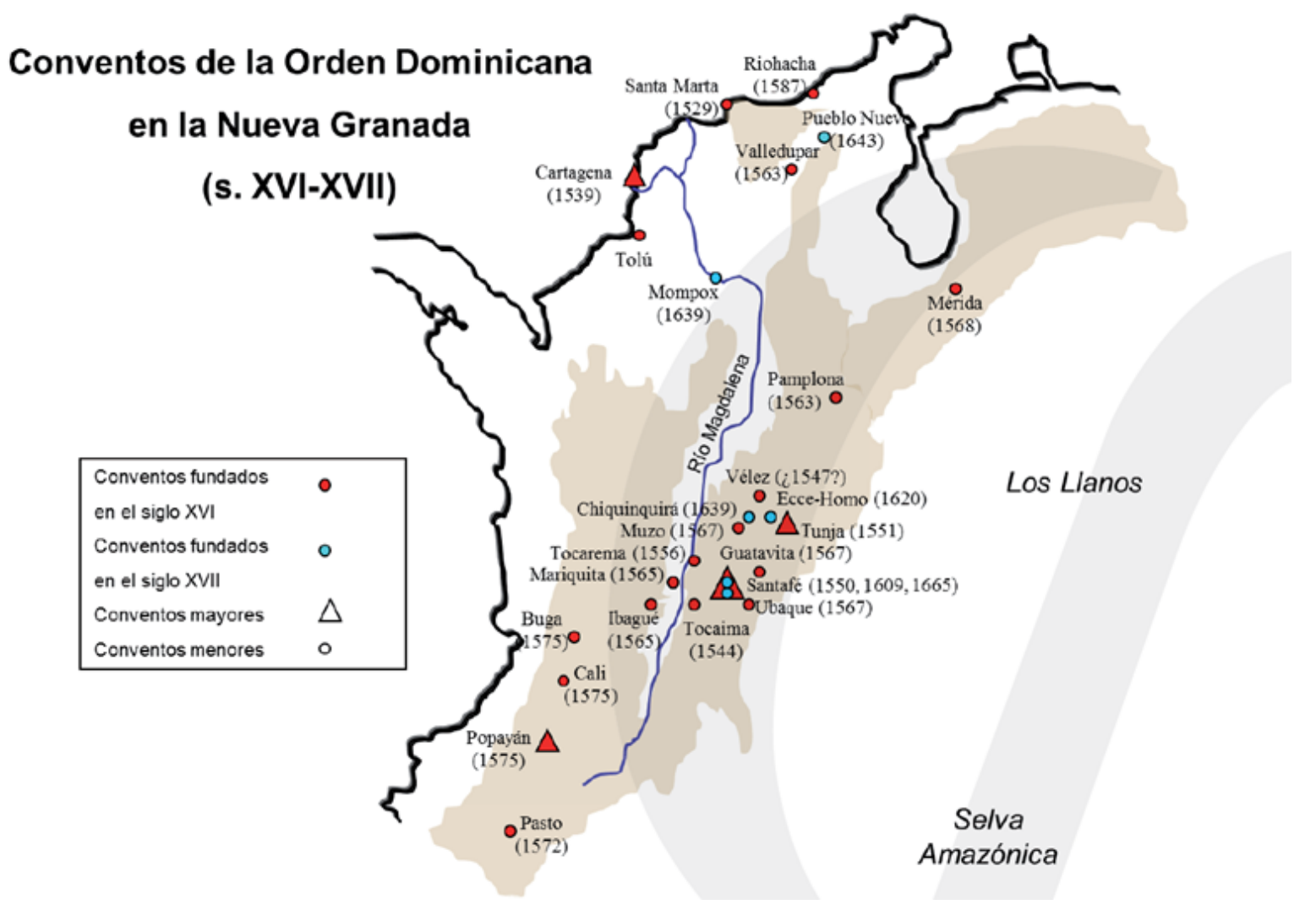

Fuente: Plata (2016, p. 276).

En la labor de los dominicos se reconoce el interés por aprender las lenguas de las comunidades indígenas y enseñarles español para cumplir su misión evangelizadora con más eficiencia, por lo que los libros tenían una gran importancia. Puede suponerse que la colección empezó a conformarse con los que los frailes traían consigo a la Nueva Granada, dado que la orden les permitía viajar con los libros de su uso:

Según la relación de cosas que los frailes dominicos llevaron a las indias en los primeros años, nos encontramos con más de 30 gramáticas de Antonio Nebrija, para los Centros de Estudio Conventuales posiblemente, dos concordancias bíblicas, las obras completas de San Agustín, Decretales, Decretos de Sexto, las Cartas Clementinas, Biblias pequeñas, las obras de Santo 
Tomás de Aquino, la Suma Doctrinal de Antonio, la Suma Angélica, seis artes de gramáticas comentas (Pérez como se cita en Universidad Santo Tomás, 2011, p. 24).

Dicha colección está compuesta por aproximadamente 6.000 volmenes, de los cuales 980 fueron impresos en España en los siglos XVI, XVII y XVII, época de la imprenta manual, por lo que representa uno de los tesoros patrimoniales más importantes del país.

El patrimonio bibliográfico que representa la colección se encuentra en manos de la Orden Dominicana, dado que, en Colombia, la Ley 1185 de 2008 establece que, en nuestro país, a diferencia de otros de la región y el hemisferio, estos bienes pueden pertenecer a la nación, a entidades pblicas de cualquier orden, a personas naturales o a personas jurídicas de derecho privado (Literal C, Artículo 4, Ley 1.185 de 2008). Por esta razón, se considera que resultados como los de la presente investigación pueden contribuir a la conservación de este patrimonio, a la divulgación de su existencia y a la promoción de la consulta del conocimiento que reposa en esta biblioteca colombiana.

\subsection{Importancia del estudio del libro antiguo en Colombia}

El libro antiguo, como documento histórico, posibilita junto a otras fuentes leer las condiciones o características de un contexto histórico particular y son invaluables para la memoria de las naciones. En países como Argentina, Brasil, Cuba y Guatemala se han constituido fondos bibliográficos de obras raras y valiosas, en los que se han hechos esfuerzos para rescatar, describir y catalogar los libros antiguos (García, 2011). En este sentido, el reconocimiento del estado de la selección de libros definida para el estudio, se suma a las buenas prácticas de conservación del patrimonio histórico y busca proporcionar una guía metodológica para el análisis gráfico y editorial de este tipo de productos en relación con el momento histórico en el cual fueron generados en Colombia (García, 2011).

En nuestro país, a diferencia de otros países de la región, existe una deuda con el rescate, el análisis y la divulgación del libro antiguo, a la que la presente investigación desarrollada pretende hacer un aporte desde el diseño gráfico: no solo porque su estudio estético, visual y material contribuye a comprender la evolución del libro en términos gráficos, sino también porque se configura en un acceso a la episteme de una época.

Este artículo aspira a convertirse en un referente para el diseño gráfico que, como disciplina, proporciona elementos del lenguaje visual y herramientas conceptuales para el análisis de productos culturales. Además, para aportar a la formación del diseñador gráfico mediante experiencias investigativas que, desde lo académico, le permiten reconocer su quehacer y proyectar sus intereses profesionales. Así como para la historia del libro, en tanto resultado editorial ubicado en el contexto nacional y latinoamericano, en la medida en que el reconocimiento de la influencia europea en la producción editorial de la época colonial permite establecer aspectos de orden identitario cultural, expresados en la elaboración, la composición, el empleo del recurso tipográfico y las temáticas de los libros antiguos.

Es necesario comprender los procesos relacionados con la historia de la producción editorial en Colombia, para dar cuenta de la memoria industrial, gráfica, artística, histórica, política, social y cultural que le ha dejado el patrimonio bibliográfico al país, reflejado en la colección de libros antiguos de la Orden Dominicana, de la Biblioteca del Convento Santo Domingo Guzmán.

\subsection{Orden de los Predicadores y desarrollo de la imprenta en el Nuevo Reino de Granada}

Como una de las primeras comunidades en establecerse en la Nueva Granada, los dominicos se concentraron especialmente en el territorio cundiboyacense, siendo protagonistas en los procesos de evangelización de una de las comunidades indígenas más grandes y más importantes en territorio colombiano: los muiscas: 
La labor desarrollada por los dominicos los convirtió en una corporación de gran poder e influencia, no solo entre los indígenas, sino además entre la población hispano-criolla, a la cual se articularon muy bien, convirtiendo a la Orden en un baluarte del orden y la sociedad coloniales (Plata, 2015, p. 81).

Las actividades de evangelización de los dominicos se destacaron, especialmente, en los temas educativos, enfocados en los principios cristianos, para lo cual los frailes contaban con una formación académica muy rigurosa en diferentes campos. Incluso, con una formación importante en las lenguas indígenas, como en el caso de Fray Bernardo de Lugo, criollo santafereño, quien estuvo a cargo de la Cátedra de Chibcha, en el Colegio Mayor de Nuestra Señora del Rosario, en Santafé de Bogotá, y fue autor de la Gramática en la lengua general del Nuevo Reyno, publicada en 1619 (Plata, 2016, p. 278).

Los libros asociados a los dominicos abordaban temas y géneros relacionados con: ejercicios espirituales semanales, sermones y conferencias, letanías, teología (dogmática, moral y apologética) de la Sagrada Escritura, filosofía, predicación, medicina, derecho civil y eclesiástico, entre otros aspectos, lo que se refleja en el corpus de la investigación.

Otro de los personajes representativos en los procesos educativos en la Nueva Granada, fue Cristóbal de Torres, quien se embarcó hacia este territorio con una biblioteca constituida en España, casi todos impresos en 1635. Esta colección, cuyos géneros incluían teología, predicación, medicina y derecho, es un buen ejemplo de una biblioteca particular del siglo XVII en la Nueva Granada, y se constituyó en uno de los primeros fondos de la Universidad del Rosario, también regentada por los dominicos en Bogotá.

Las colecciones de las órdenes religiosas se enriquecieron con la llegada de la imprenta a la Nueva Granada en 1735: "por medio de la compañia de Jesús, llegan a Cartagena de Indias 'tres cajones de letra imprenta' dirigidas al Colegio Máximo de la Compañía de Jesús, el Colegio de San Bartolomê" (Rubio, 2017a, p. 57). La imprenta, a cargo de Francisco de la Peña, obtuvo un permiso provisional de la Real Audiencia de Santafé en 1737 "para imprimir algunos libros de doctrina de devoción" (Rubio y Murillo, 2017, p. 54), el cual le fue negado posteriormente por la Corona en 1741. Pese a esto, la imprenta siguió funcionando hasta la expulsión de los jesuitas en 1767.

En 1938 esta imprenta produjo los que se consideran los primeros textos impresos en la Nueva Granada, en hojas sueltas alusivas a la doctrina religiosa, y el primer libro impreso en Colombia: El Septenario al corazón doloroso de María Santíssima, de Juan Vicente Ricaurte. Sin embargo:

La imprenta de los jesuitas no funcionó con regularidad, era escasa su producción y los métodos empleados para ella,
artesanales y lentos, habituales de las prensas de madera de la época. Los trabajos de impresión de Francisco de la Peña, en
su mayoría son escritos de la Compañía dedicados a su labor evangelizadora y docente, y muestran deficiencias en la calidad
de impresión, donde se aprecia un reparto desigual de la tinta y el uso de tipos rotos y deteriorados de letra romana redonda
y cursiva. Las "letras de imprenta" que en cajones llegaron desde España en 1735, posiblemente eran tipos ya usados por la
propia Compañía que, al menos desde el último cuarto del siglo XVII, se dedicó a fundir caracteres, tuvieron las matrices
en propiedad y las cedían en alquiler a varios fundidores hasta bien entrada la segunda mitad del siglo XVIII (Rubio, 2017a,
p. 58).

Es precisamente esta escasa y espaciada producción tipográfica la que hace que se considere que el inicio de la actividad editorial en la Nueva Granada se dio décadas después a la fundación de esta imprenta (Rubio y Murillo, 2017). No fue sino hasta luego de 11 años de la expulsión de los jesuitas, con la creación de la Imprenta Real en 1778, que se dio comienzo a la producción continuada de textos impresos cuando, por orden del virrey Manuel Antonio Flórez, el impresor Antonio Espinosa de Monteros, llegó a Bogotá, desde Cartagena de Indias, para hacerse cargo de esta imprenta (Rubio, 2017b, p. 18).

El primer libro producido en la Imprenta Real fue Premios de la obediencia, castigos de la inobediencia en 1782; obra del sacerdote franciscano Raymundo Azero en la que se hace una exhortación doctrinal, en latín y en español, a favor de la sumisión a la corona española. Esta obra es la publicación del sermón que el padre Azero hizo en la plaza mayor de la capital el 1 de febrero de 1781, después de la ejecución de los líderes de la 
Revolución de los Comuneros, que inspiraría, posteriormente, el movimiento independentista en la Nueva Granada (Melo, 2020, pp. 38-39).

La Imprenta Real atravesó por diversas dificultades tanto económicas como de acceso y calidad de los insumos tipográficos:

La carencia de tipos y los altos precios que alcanzaban en el extranjero y en la fundición de los pocos juegos de matrices disponibles en España, hizo que los impresores trabajaran con viejas fundiciones que iban pasando de un profesional a otros por venta o herencia. Fue así frecuente que los impresores utilizaran, y es el caso de Antonio Espinosa, letra defectuosa y en mal estado tras una excesiva reutilización de los tipos. A esto se añadían las carencias que presentaban muchas de las nuevas fundiciones, generalmente defectuosas y de escasa duración por el empleo de metales de poca calidad o el desconocimiento de la mezcla adecuada (Rubio, 2017a, pp. 58-59).

Con estas limitaciones, la Imprenta Real publicó fundamentalmente calendarios, reformas administrativas, carteles e informaciones sobre higiene y control de epidemias, además de oraciones, devocionarios, sermones y novenas financiadas por las comunidades religiosas; así como la Gaceta de Santafé, creada en 1785 como la primera experiencia de prensa oficial que solo alcanzó tres números (Guarín, 2011, p. 3). Sin embargo, pese a estas:

En la Imprenta Real se editaron obras significativas por su calidad de impresión y por sus dimensiones de paginación, como la reimpresión en 1784 del Arte de construcción, de Fray Pedro Masustegui, con 197 páginas; la conocida traducción del latín al castellano de la Historia de Christo paciente, hecha por el sacerdote José Luis de Azuola e impresa en 1787, con dos tomos de extensión de 230 y 264 páginas cada uno; la Historia de las ciencias naturales en castellano de Alexandre Saverien, editada en 1791 con 425 páginas de extensión en su totalidad; o el Tratado de la fuerza de la fantasía humana del ilustrado italiano Luis Antonio Muratori, editado en 1793 con una extensión de 342 páginas (Rubio, 2017a, p. 63).

Aunque la producción e impresión de textos en la época colonial requería permisos y licencias reales (Melo, 2004, párr. 6), a finales del siglo XVIII prosperó, en la Nueva Granada, la idea de poseer imprentas privadas. Tales son los casos de la Imprenta Patriótica de Antonio Nariño creada en 1793, la cual imprimió la traducción de Los derechos del hombre y del ciudadano, y la Imprenta Espinosa propiedad de Antonio Espinosa y sus hijos que, bajo su propio sello, reprodujo las constituciones republicanas existentes a la fecha (Guarín, 2011, p. 4). En los siglos precedentes, es decir, siglo XVI y XVII, la situación que se vislumbraba en torno a las imprentas era la siguiente:

Durante el siglo XVI (...) las cartillas de lectura, la liturgia (breviarios, diurno, misales) y el rezo (horas), lecturas directamente vinculadas a la cristianización y alfabetización de la población indígena, representaron el mayor porcentaje de libros importados a las Indias. A pesar de la precariedad del mundo editorial español, que debía recurrir a impresiones del extranjero, a fines del siglo el número de los registros de libros aumentó ligeramente con diversificación de autores, géneros y títulos que exigía la demanda vinculada al desarrollo de la colonización y de la imprenta. Durante la primera mitad del siglo XVII, la eclosión burocrática, el establecimiento de centros educativos (colegios, centros religiosos, universidades) y el incremento de inmigrantes impulsaron el comercio libreo que tendrá como lectores a los sectores sociales que utilizan el libro como necesidad laboral. Destacan los religiosos, los funcionarios, las profesiones libres, los mercaderes, los militares y los grandes hacendados (Rubio, 2017b, p. 9).

En el siglo XVIII, la edición tuvo un notable incremento con la demanda de textos de ciencias modernas y técnicas: el libro científico, "este hecho hay que relacionarlo con la Ilustración, fenómeno de divulgación del conocimiento moderno y del desarrollo material, que impulsará cambios culturales en la sociedad neogranadina antes y después de su proceso revolucionario que inició en 1810" (Rubio, 2017b, p. 16).

\subsection{El análisis del libro antiguo}

Las colecciones de libros antiguos formadas en la época colonial en Colombia por particulares, instituciones públicas u órdenes religiosas son "un reflejo de lo que se publicaba, lo que circulaba, de las 
preocupaciones de una profesión, de una comunidad, de una época, y de alguna manera dan testimonio de la formación de unos espacios públicos o privados y de su influencia cultural e ideológica" (Rubio, 2013, p. 30).

En Colombia, por la influencia de los libros y periódicos producidos a finales del siglo XVIII en el pensamiento ilustrado que sustentó los movimientos independentistas, las investigaciones sobre el libro antiguo se han concentrado en ese periodo. Se trata de una tendencia "relacionada con la larga tradición de la historiografia tradicional colombiana de tomar del pasado colonial solo aquello que ha sido concebido como precursor de la Independencia" (García, 2015, p. 19), dejando de lado la producción editorial de los siglos XVI y XVII, concebida como producto de un pasado colonial homogéneo y carente de interés (García, 2015).

Segn García (2015), importantes estudios como el Leonard Irving, con su obra Los libros del conquistador (1996), rompen con la "leyenda negra" de que el dominio de España sometió a sus colonias americanas a una suerte de oscurantismo intelectual, sustentado en que, en los siglos XVI y XVII, "bubo un gran comercio de libros entre la metrópoli y sus colonias, de tal manera que la distancia cultural no era tan grande como se pensaba" (García, 2015, p. 21). Estos postulados permiten apreciar en su real magnitud el aporte de las colecciones de las comunidades religiosas en el contexto sociocultural de la colonia en la Nueva Granada, como el de la Biblioteca Santo Domingo de Guzmán.

Chartier (1996) plantea que un libro tiene dos componentes básicos: por un lado, el objeto físico, que tiene una materialidad específica, y por el otro, el discurso que transmite al lector. En su elaboración intervienen el autor y el impresor; pero, también el editor, los cajistas y los ilustradores; a los que se deben agregar las máquinas y tecnologías necesarias para su producción Este proceso da lugar a la comunicación escrita de ideas y a la lectura, es decir, al entramado lógico y discursivo que le permite exponer su mundo al autor y ser interpretado por el lector. Aunque los dos componentes del libro: objeto físico y discurso estén unidos de manera íntima, de tal manera que uno no existe sin el otro, metodológicamente pueden ser divididos para facilitar su estudio. Además, es necesario "comprender, de la mano de McKenzie (1999) y Chartier (2000) que los textos no pueden existir por si mismos, por fuera de las 'materialidades' que los vehiculan, ya que son éstas las que permiten que los textos sean leidos, escuchados y vistos" (Bedoya, 2011, p. 106).

La descripción de libros, desde su materialidad, ya se realizaba en el siglo XVIII; esa práctica se convertiría, a finales del siglo XIX, en un estudio sistemático con carácter histórico, dada la necesidad de las bibliotecas nacionales de registrar el patrimonio bibliográfico expropiado a la iglesia católica, y así poder determinar su valor cultural.

La Bibliographical Society, fundada en 1892, se encomendó a la tarea de establecer prácticas y principios para la comprensión del libro antiguo. Esta reflexión sobre el objeto les daría gran importancia a los conceptos de edición, transmisión y estado, así como a la representación de las variables sobre esas tres áreas. Este conocimiento se integraría a las tareas de catalogación que permitieron reconocer las características especiales de estos libros.

El reconocimiento actual del libro antiguo, como un objeto conformado por valores textuales e históricos, soporta y justifica su comprensión patrimonial. Su conjunto de atributos es lo que permite entender y conocer el libro como un producto de su tiempo y en relación con sus semejantes. Al mismo tiempo, permite valorar la historia de estos libros como productos sociales que han sido poseídos y utilizados (García, 2018, p. 28).

Desde la bibliografía material, se plantean como categorías para el estudio del libro antiguo: la identificación y la descripción previa del material, el detalle de portada y del pie de imprenta, las marcas tipográficas, el tamaño y los formatos; el tipo de letra y los reclamos, los elementos ornamentales, los preliminares y el texto, las marcas de fuego, los exlibris y los sellos, las anotaciones manuscritas y los testigos, la encuadernación, el estado de conservación, la ubicación física del material, las referencias bibliográficas y la existencia de otros ejemplares (García, 2011).

A estas categorías, se pueden agregar otras que ha trabajado la Biblioteca Nacional de Colombia en el Fondo Antiguo, y que han permitido el estudio profundo de los aspectos materiales e inmateriales de los libros: las signaturas, la ciudad de impresión, el papel, el idioma, el impresor, la marca del impresor, las medidas, los 
folios, los tipos de letra, el uso y las características de las letras capitales, el colofón, la encuadernación, la marca de agua, las tintas, las tablas de contenido, las inscripciones manuscritas, la notas o huellas del lector, los dueños y sellos.

Estas categorías permiten, no solo la categorización y el reconocimiento de las características y particularidades del libro antiguo, sino también la reflexión sobre la importancia de su valor histórico y patrimonial.

\section{Metodología}

El estudio gráfico e histórico de libro antiguo que se hizo en la investigación se desarrolló mediante un proceso que partió del análisis descriptivo para dar paso, posteriormente, a un análisis de los aspectos materiales y gráficos del libro. Presentó un enfoque descriptivo orientado a conocer el libro como objeto cultural y sus características específicas, con lo cual se inscribe en los estudios de la historia cultural.

La elección de las obras dentro de la colección de libros antiguos de la Biblioteca del Convento de Santo Domingo Guzmán, se hizo teniendo en cuenta criterios específicos: que fueran libros de los siglos XVI, XVII y XVIII impresos en una misma ciudad, elaborados por un solo impresor, con presencia de grabados y con rastros de lectores.

Una vez seleccionados los libros, se aplicó una base de datos con cerca de 40 campos, que fue diseñada y aplicada en una investigación sobre los incunables de la Biblioteca Nacional de Colombia, en la que también participó la autora de este artículo.

Dicha base de datos permitió describir los libros, tanto bibliográfica como gráficamente, atendiendo a los siguientes campos: la signatura en la Biblioteca, el título, el autor, la fecha de impresión, el nombre de los impresores o talleres tipográfico, la marca del editor, la ciudad de impresión, el númerđe edición, la marginalia, los grabados, el tamaño del papel, las capitales (grabados e iluminadas), la portada, los reclamos, la signatura, el registrum, la cantidad de colores de tintas, el idioma, las temáticas y subtemáticas, el tipo de encuadernación, la maculatura (tapas, guardas y encuadernación), los dibujos a mano, las inscripciones manuscritas. Estas características, examinadas en conjunto, permiten disponer las lógicas de la producción bibliográfica en determinado periodo; en este caso del siglo XVI y primeras décadas del siglo XVII, en términos de la composición de portadas, del uso de marcas de impresor, del uso de las tintas, y que permitieron describir bibliográfica, histórica y gráficamente una parte de la colección.

El enfoque metodológico de la investigación fue mixto, pues se sustentó en recursos y herramientas cualitativas y cuantitativas para determinar y analizar las categorías de la investigación. Las etapas del desarrollo de la investigación fueron: i) identificación previa: descripción de la organización de la colección, es decir, ubicación y jerarquización, ii) detalle material del libro: tamaño, encuadernación, marcas de agua, tipo de papel, páginas, estructura del cuadernillo, etc., iii) descripción de aspectos relacionados con el diseño: tipos de letra, colores, marcas de impresor, otras marcas, tipología de grabados, cantidad de ornamentos, idioma, etc., iv) caracterización de la portada: imágenes (grabados en madera o metal) y letras; datos de la obra, tipo de portada: simple, portada a dos tintas, portada orlada, portada con orla tipográfica, portada enmarcada, portada grabada, v) rastros de lectores: marcas de propiedad manuscritas o sellos, notas de lectura, testimonios de otros eventos (expurgos por parte de la Inquisición o acontecimientos personales), dibujos, etc., y vi) análisis de las marcas tipográficas, tipos: anagrama, monograma, alegoría, viñeta, u otros signos que hacen parte de las portadas. 


\section{Resultados}

En 1551, después de 11 años de su llegada a la ciudad de Tunja, los frailes dominicos fundaron el Convento de Santo Domingo de Guzmán y crearon la primera Escuela de Gramática para la educación de criollos e hijos de caciques (USTA, 2011, p. 18).

Para enseñar a los indígenas a leer, a contar, gramática y lengua española, plantel que admitió también mestizos e hijos de Caciques, pues en sus aulas completaron su educación los célebres Caciques de Turmequé, don Diego de Torres, y de Tibasosa, Alonso de Silva, quienes cursaron: Religión, Moral y Gramática. El Padre Alberto Ariza dice que en esta escuela no había distinción de clases sociales, pues aquí estudiaban plebeyos, ricos, pobres, negros, indios (USTA, 2011, p. 19).

El Convento se instaló en el centro de la población (actualmente carrera 11, entre calles 19 y 20) y, en 1560 se inició la construcción del templo: "Para 1610 el convento está completamente terminado y luego en 1628 es terminada la construcción del Templo" (Rueda y López, 2014, p. 7).

En 1608, el capítulo general de Minerva de la Orden de los dominicos, celebrado en Roma ese mismo año, decretó "Instituimos y erigimos en Estudio General o Universidad nuestro Convento de Santo Domingo Tunja, por su comodidad y aptitud para sustentar a los religiosos, siguiendo las leyes establecidas entre la Corona Española y el Patronato Real" (como se cita en USTA, 2011, p. 20). De este modo accedió a la categoría de Universitas Magistrorun et Scholarium, impartiendo una enseñanza apoyada en el modelo de la Universidad de Salamanca, de donde procedían muchos de sus frailes.

En 1863, el gobierno de la época hizo cumplir el decreto del 5 de noviembre de 1861 que ordenaba la extinción de todos los conventos, monasterios o casas religiosas, expedido por el general Mosquera. Motivo por el cual se cierra el Convento que es tomado por las tropas del gobierno y, por orden del Presidente del Estado de Boyacá, los religiosos son desterrados a los Llanos Orientales (USTA, 2014, p. 52). En 1881 se restaura la orden y, en 1916, se inicia la construcción, en la ciudad de Tunja, de un nuevo edificio estilo republicano (Rueda y López, 2014, p. 7) (ver figura 2).

FIGURA 2

Edificios de los Conventos de Santo Domingo de Guzmán, Tunja.

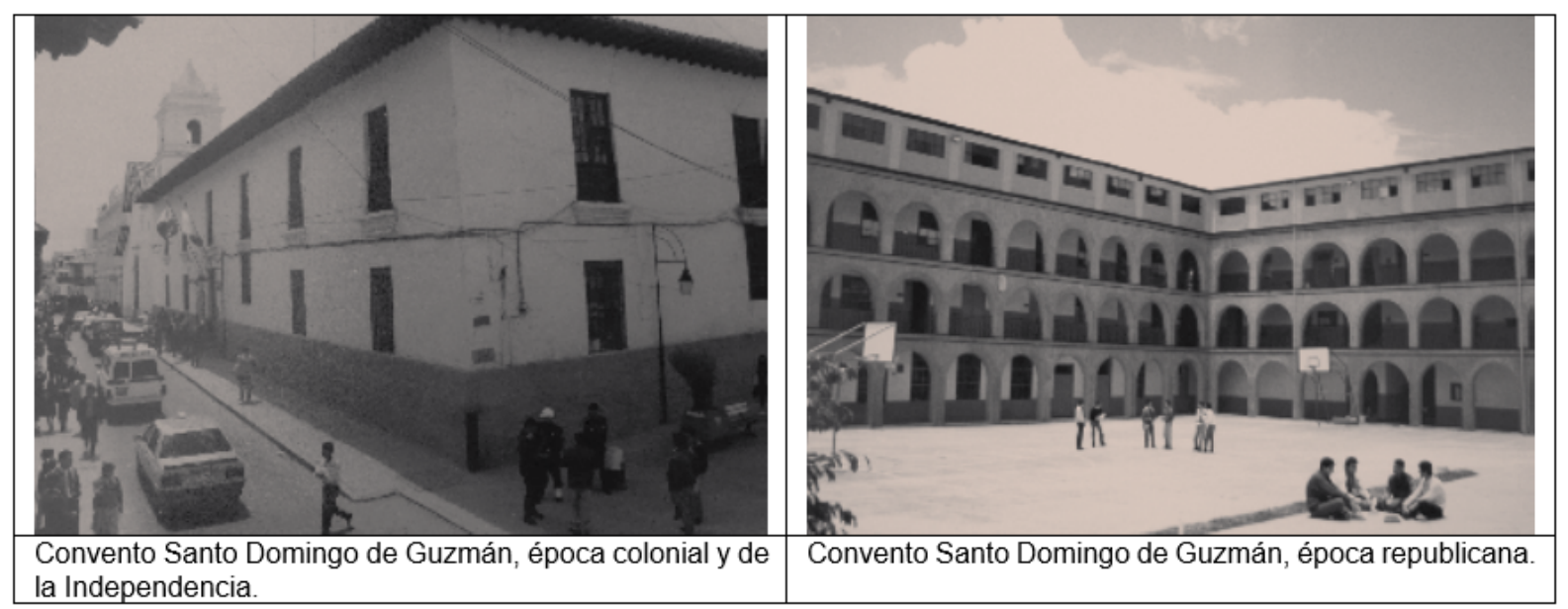

Fuente: USTA (2014, p. 63).

El edificio republicano que se inició en el año 1916 fue construido en la esquina sur del que fuera el primer Convento de Santo Domingo, en el que actualmente funciona el edificio de la Policía Nacional. Para lo cual, los dominicos ocuparon y construyeron posteriormente edificaciones aledañas, como el Liceo Santo Domingo en 1954, de tal forma que el emplazamiento existente en 1996, cuando se inicia su intervención para albergar a la Universidad Santo Tomás de Tunja, se describe de la siguiente manera: 
Este inicia su lado oriental con la parte sur del templo de Santo Domingo y con la carrera 11 hasta llegar a la esquina de la carrera 11 con calle 19 (...) girando noventa grados hacia el occidente de la ciudad continúa la construcción de influencia republicana que remata con edificación neoclásica también, y sigue con las edificaciones de los años cincuenta donde funcionaba el Liceo Santo Domingo (USTA, 2014, pp. 62-63).

En el 2000, en la celebración de los 450 años de la Comunidad Dominicana, se inició la construcción del nuevo Convento de Santo Domingo de Guzmán, en los cerros nororientales de Tunja (calle 48 No. 1-135). Fue inaugurado en 2002 junto con la instalación de la sede del campus universitario de la Universidad de Santo Tomás (ver figura 3).

FIGURA 3

Instalaciones de la orden dominicana en Tunja.

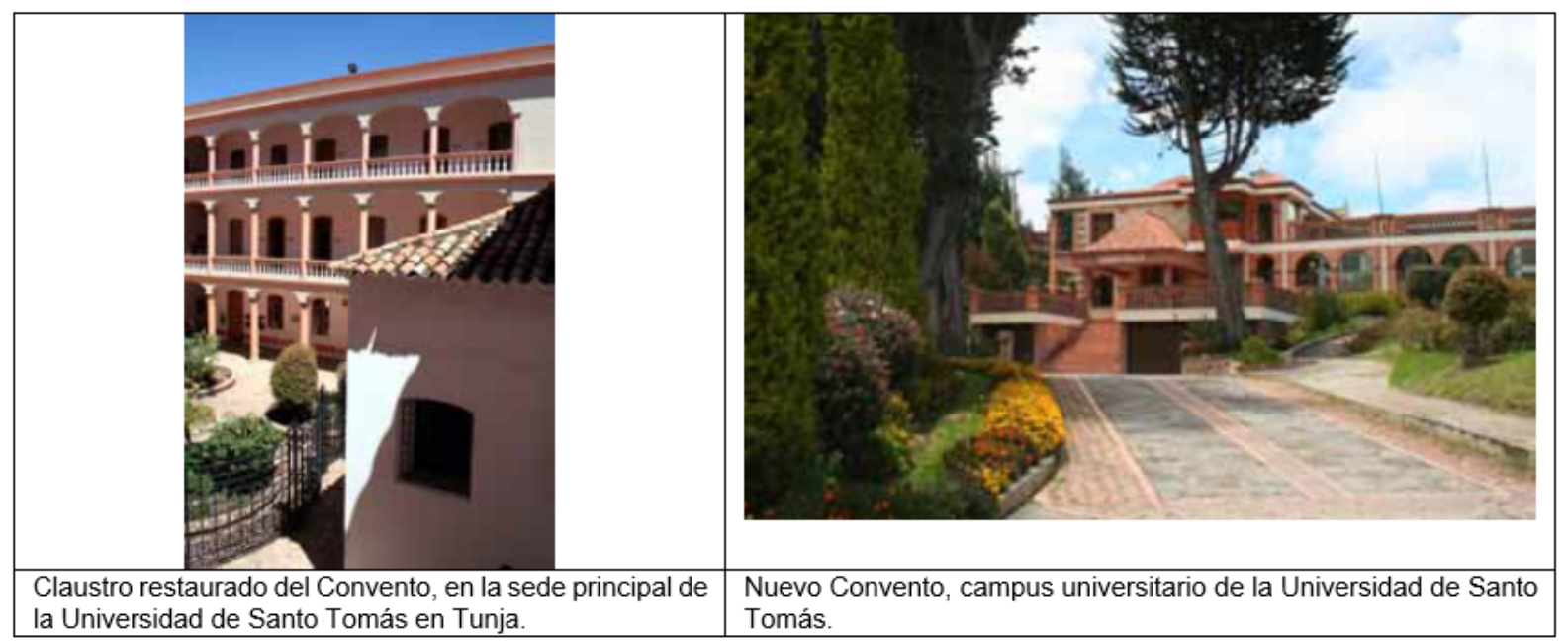

Fuente: USTA, 2014.

La colección de la Orden de los Predicadores está ubicada en la Biblioteca que funciona en las instalaciones del convento en el campus universitario de la Universidad Santo Tomás. Sus volúmenes están distribuidos en diferentes espacios de la Biblioteca. El grupo de investigación tuvo autorización para trabajar con los libros ubicados en la biblioteca dispuesta para el estudio de los seminaristas, que tiene dos niveles. En el primer nivel hay una sala de lectura con textos actuales de todo tipo y, en el segundo, en una sala de lectura que tiene iluminación por cuatro ventanales, se ubican 922 libros. Estos ejemplares fueron producidos entre el siglo XVI y el siglo XX; por lo que hay libros antiguos y modernos.

La muestra a la que se accedió en la investigación fue la de los libros de la sala de lectura del segundo nivel, de los cuales se identificaron 400 de ellos correspondientes a los periodos de estudio del proyecto (siglos XVI, XVII y XVIII). Posteriormente, se seleccionaron 52 como corpus de estudio a partir de la fecha de edición. Cabe destacar que esta recolección fue realizada pese a la falta de información precisa sobre su producción y con base en el análisis e interpretación de las categorías de la investigación; entre estos, los datos de impresores, de licencias, de ciudad, de temáticas, de ilustraciones y de signaturas, etc. (ver figura 4). 
FIGURA 4

Ubicación de los libros antiguos en la Biblioteca Santo Domingo de Guzmán.

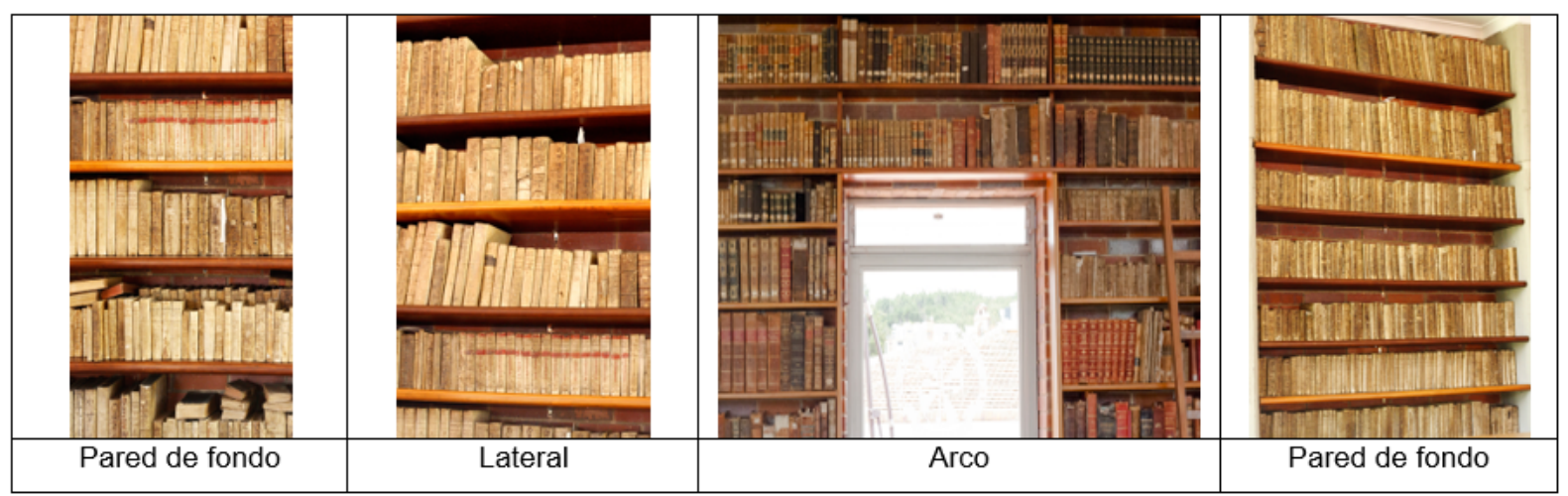

Fuente: elaboración propia.

Estos libros antiguos están dispuestos en estantes contra las paredes de la sala de la Biblioteca. La selección de la muestra de 52 libros se basó en la idea de reconstruir la composición de una biblioteca en una ciudad colonial, con base en el análisis de los catálogos y formas de organización de los libros dentro de la colección, lo que, según Burke (2002), es uno de los principales aportes del desarrollo de las bibliotecas, de la mano de la imprenta, la circulación y la difusión del conocimiento. La determinación de las líneas temáticas de los libros en el registro y los rastros de lectores, permitieron, por una parte, segmentar el objeto cultural y, por otra, elaborar una idea de la biblioteca como unidad. Esto facilitó la circulación del conocimiento y la comunicación a través de la imprenta en la época de la Colonia en Colombia, siguiendo a Darnton (1982) quien afirma que la historia del libro es historia social de la comunicación impresa.

El espacio en el que están ubicados los libros es una sala con tapetes, y están expuestos a la luz y al aire; además, el acceso a los mismos no está regulado. No hay un sistema o protocolo de conservación para los libros, por lo cual la mayoría tiene algún tipo de deterioro en alguna de sus partes; en especial, aquellos más antiguos (ver figura 5).

FIGURA 5

Muestra del estado de deterioro de la colección.

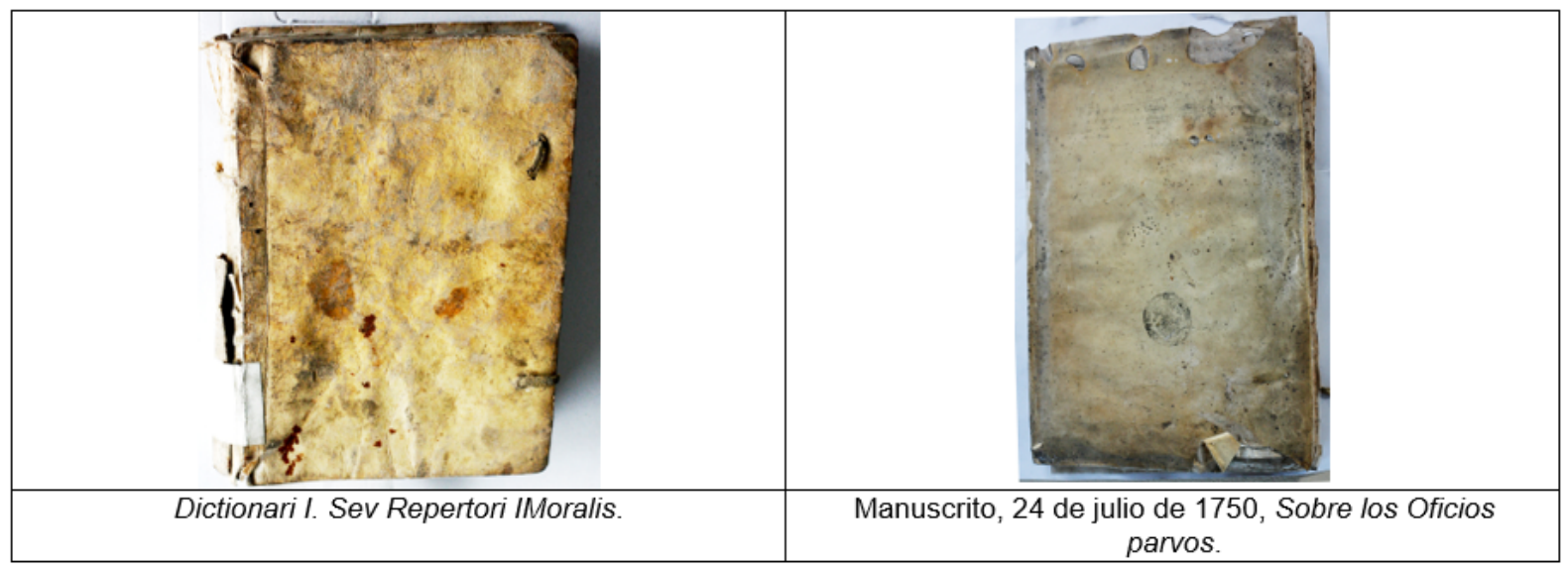

Fuente: elaboración propia.

Se pudo constatar que no existe una catalogación propia de estos libros, por lo cual no se conoce con certeza cuántos libros hay en el convento, lo cual obligó a contarlos de forma pormenorizada a fin de definir las temáticas, los formatos, los temas, etc. 
Con el propósito de determinar el número de libros antiguos en la colección y sus características, se identificaron de acuerdo con el estante en el que se ubicaban. Los resultados se presentan en la siguiente tabla (ver tabla 1 ).

TABLA 1

Ubicación de los libros antiguos de la colección.

\begin{tabular}{|l|l|l|l|}
\hline ESTANTES & PARED 1 & PARED 2 & PARED 3 \\
\hline 1 & 56 & 39 & 12 \\
\hline 2 & 46 & 38 & 24 \\
\hline 3 & 38 & 39 & 28 \\
\hline 4 & 37 & 78 & 8 \\
\hline 5 & 44 & 44 & 0 \\
\hline 6 & 33 & 53 & 0 \\
\hline 7 & 106 & 49 & 0 \\
\hline 8 & 47 & 41 & 0 \\
\hline 9 & 31 & 31 & 0 \\
\hline TOTAL & 438 & 412 & 72 \\
\hline
\end{tabular}

Fuente: elaboración propia.

En la siguiente lista se presentan los títulos de los 52 libros elegidos como corpus de estudio (ver tabla 2).

TABLA 2

Lista de libros del corpus de estudio.

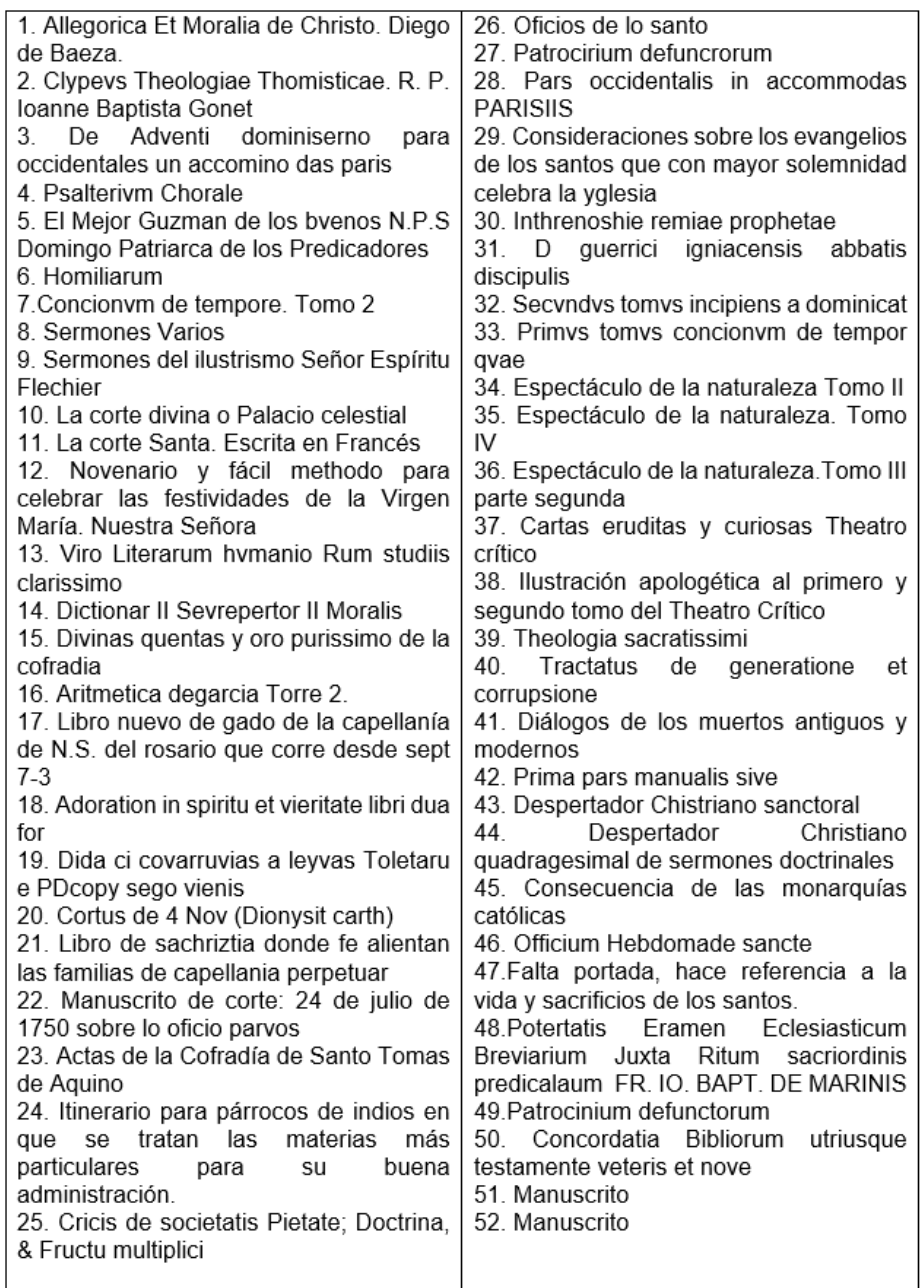

Fuente: elaboración propia. 
El registro de los libros seleccionados se hizo en una matriz que contiene los siguientes datos: título del libro, autor, año de publicación, identificación y descripción previa del material, descripción de portada y pie de imprenta, marcas tipográficas, tamaños y formatos, tipos de letra y reclamos, elementos ornamentales, preliminares y texto, marcas de fuego, exlibris y sellos, descripción de portada y pie de imprenta, anotaciones manuscritas y testigos, encuadernación, ubicación física del material, referencias bibliográficas y otros ejemplares, marcas del impresor, folios, tipos de letra, capitales, colofones, huellas del lector.

Los libros analizados cumplen con las pautas establecidas para la censura y aprobación de libros del Concilio de Letrán [1515], que estableció el control sobre los contenidos, materias y procedencia. En 1558, la inspección se conituyó como Orden real, en la Pragmática sobre la impresión y libros licencia por el Rey y el Concejo:

El que el Consejo Real se reservase la facultad de conceder la licencia y el privilegio para imprimir, por medio de una de sus secretarías o por el juez de imprentas, no quiere decir que no estuviese mandada la censura previa eclesiástica, pues ya estaba clara y expresamente desde Alejandro XI y de hecho la ejercían los ordinarios por medio de los Vicarios generales de la diócesis y de los prelados regulares, existiendo registros y expedientes relaticos a ella y figurando frecuentemente en los preliminares de las obras publicadas (Sierra, 2009, p. 25).

De acuerdo con lo anterior, los elementos con los que debían contar los libros que ingresaron a América, y que aparecen en la colección, son: portada, dedicatoria, privilegio, aprobación o aprobaciones de la autoridad civil, licencia de la autoridad civil, aprobación o aprobaciones de la autoridad eclesiástica, licencia de la jerarquía eclesiástica, aprobación o aprobaciones de superiores del clero, licencia de orden religiosa, fe de erratas, tasa, escritos en prosa de otros autores, poesías del propio autor, poesías laudatorias de otros autores y prólogo (ver figura 6).

FIGURA 6

Pautas del Concilio de Letrán en los libros antiguos de la colección.

\begin{tabular}{|c|c|c|c|c|}
\hline 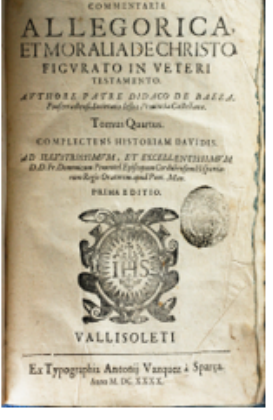 & 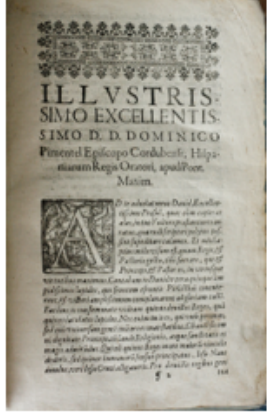 & 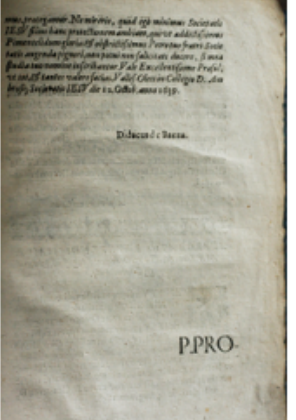 & 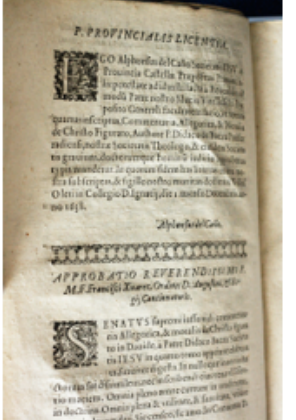 & 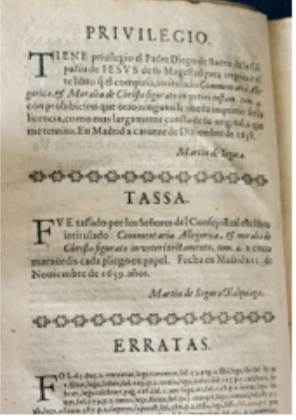 \\
\hline $\begin{array}{c}\text { Allegorica Et } \\
\text { moralia De Christo } \\
\text { figurato in Vereti } \\
\text { testamento. Tomus } \\
\text { Quartus }\end{array}$ & $\begin{array}{c}\text { Allegorica Et } \\
\text { moralia De Christo } \\
\text { figurato in Vereti } \\
\text { testamento. Tomus } \\
\text { Quartus }\end{array}$ & $\begin{array}{c}\text { Allegorica Et moralia } \\
\text { De Christo figurato in } \\
\text { Vereti testamento. } \\
\text { Tomus Quartus }\end{array}$ & $\begin{array}{l}\text { Allegorica Et moralia } \\
\text { De Christo figurato in } \\
\text { Vereti testamento. } \\
\text { Tomus Quartus }\end{array}$ & $\begin{array}{c}\text { Allegorica Et moralia } \\
\text { De Christo figurato in } \\
\text { Vereti testamento. } \\
\text { Tomus Quartus }\end{array}$ \\
\hline
\end{tabular}

Fuente: elaboración propia.

Las portadas, en su mayoría impresas en una o dos tintas con presencia de múltiples elementos ornamentales tipográficos, están compuestas por el título de la obra, las líneas que dividen los textos, los filetes decorativos, los tacos tipográficos, las hojas, las estrellas, las autorizaciones, los grabados y los impresores. Sobre estos últimos, se pueden mencionar a: Antonio Pérez de Soto, Antonio Vazquez y Esparza, Nicolai Angeli Tinafsij, ex officina Christophori Plantini architipographyregij, Blas Román, Gabriel Ramírez, Apud Gafparem Bindonum, Juan de Zúñiga, Balthasaris Moreti, Pedro Marín, Ex officina typographica Jo. Mathiæ Hovii, Pedro Madrigal, Gabriel Ramos Bejarano, Jayme Osset, Benito Cano, Joseph y Tomas de Orga, Benito Monfort, Joseph Rodríguez y Escobar, Andrés García, Pablo de Val, Gregorio Hermosilla, Juan Piferrer, Pedro Escuder, Manoel Soares, Pauli Mauli, Ioannis Barrerij, Bernardo Acosta Carvalho, Manuel Martin, 
Luys Sánchez, Melchor Sánchez, Pedro Marín, Joaquín Ibarra, Antonio Muñoz Del Valle, Herederos de la viuda de Juan García Infanzón, Juan Flamenco, Juan-Maria Salvioni Tipografía del Vaticano, Typographia Balleoniana, Hieronymi Mainardi y Apud Ioannem Keerbergium (ver figura 7).

\section{FIGURA 7}

Portadas de libros antiguos de la colección.

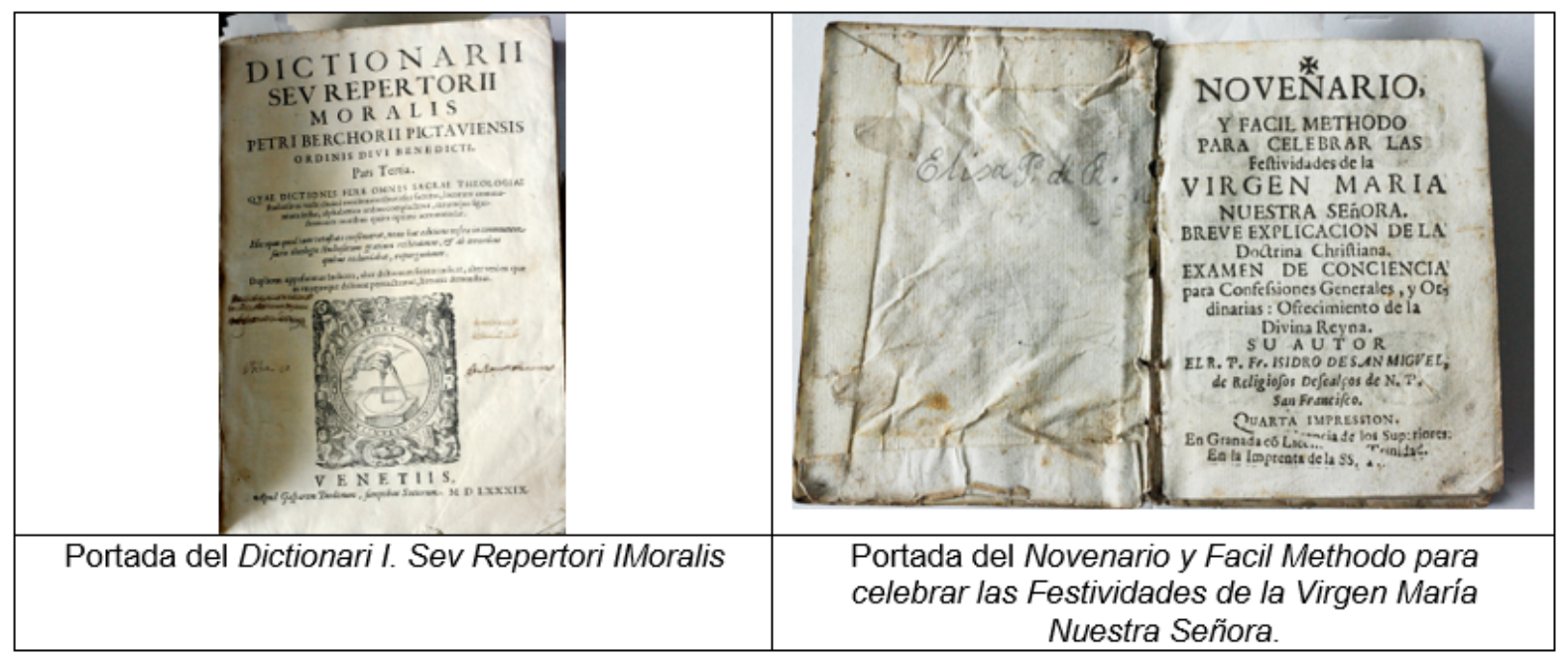

Fuente: elaboración propia.

En los libros antiguos del corpus, se constató la presencia de manuscritos, en tanto categoría establecida en la investigación para clasificarlos, como el libro Nuevo de gastos de la capellanía de N.S. de el Ross (ver figura 8).

FIGURA 8

Libro manuscrito, Nuevo de gastos de la capellanía de N.S. de el Ross.

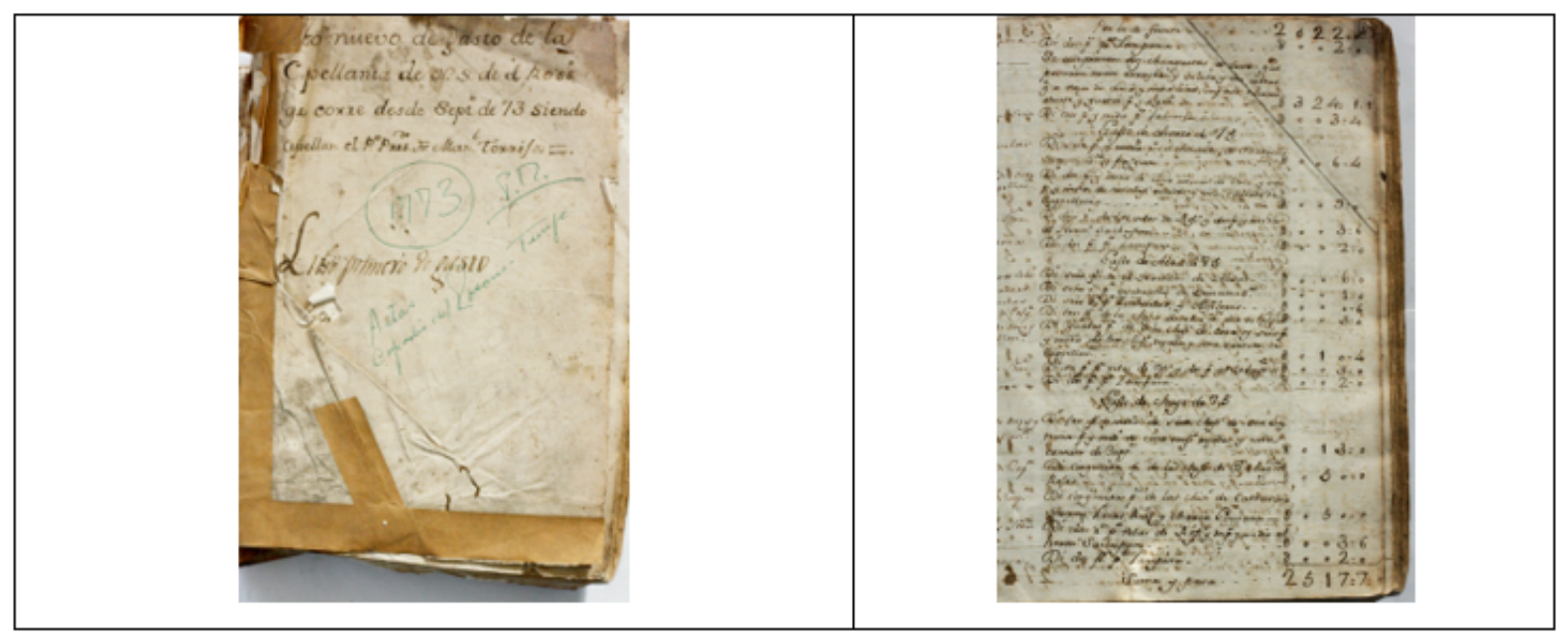

Fuente: elaboración propia.

Así como de libros manuscritos antiguos, entre los que se destacan los de $22.5 \mathrm{~cm}$. x $32 \mathrm{~cm}$. (ver figura 9). 
FIGURA 9

Libros manuscritos de la colección.

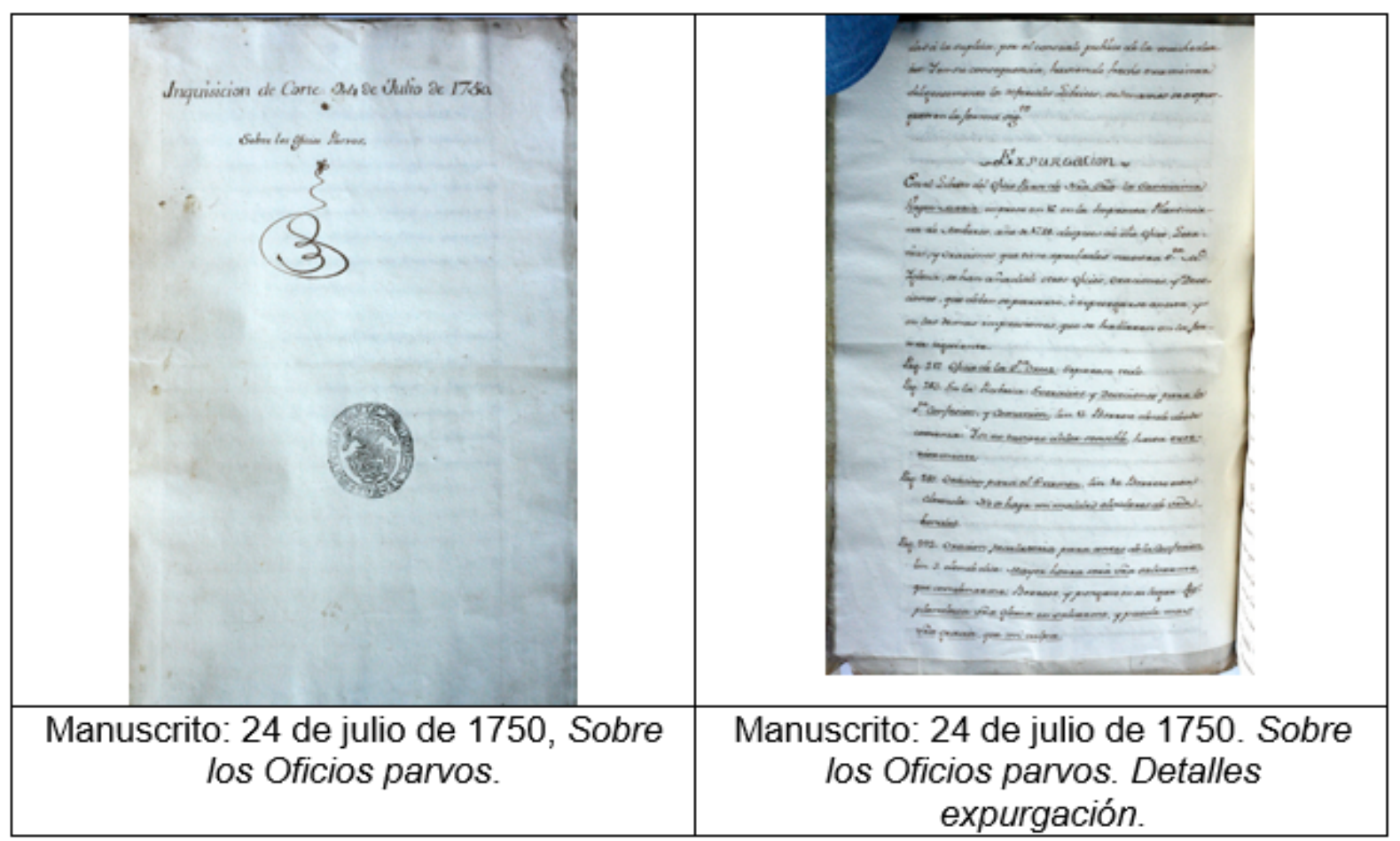

Fuente: elaboración propia.

También se pudo constatar la existencia de las técnicas de grabado determinadas para el reconocimiento y la clasificación de los libros antiguos en el corpus de la investigación, como el grabado xilográfico en las portadas y de cierre, y llamados de texto (ver figura 10).

FIGURA 10

Grabado xilográfico en los libros de la colección.

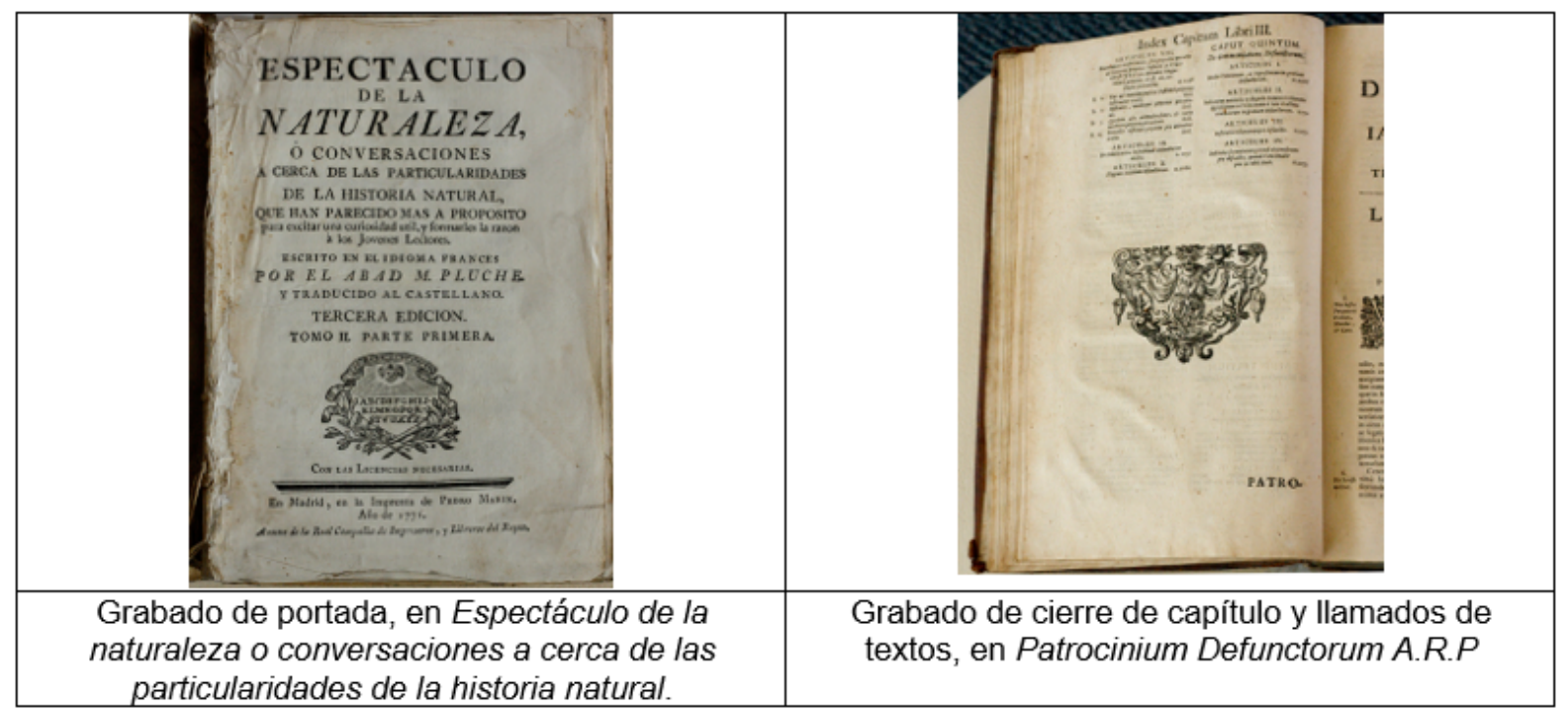

Fuente: elaboración propia.

Igualmente se pudo observar la técnica con grabado de cobre en inserciones en estos libros antiguos (ver figura 11). 
FIGURA 11

Insertos con grabado con lámina de cobre, en el libro Espectáculo de la naturaleza o conversaciones a cerca de las particularidades de la historia natural.

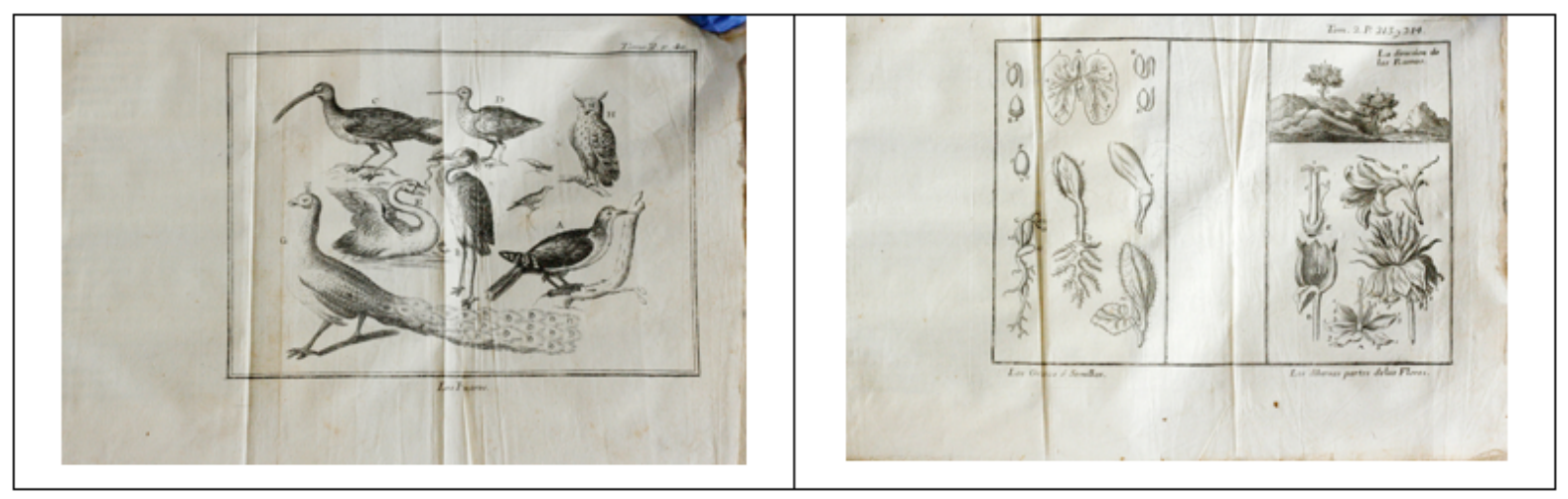

Fuente: elaboración propia.

Otra de las características relevantes para la identificación y la clasificación de los libros antiguos son las marcas o rastros de lectores (ver figura 12).

FIGURA 12

Rastros de lectores en los libros antiguos.

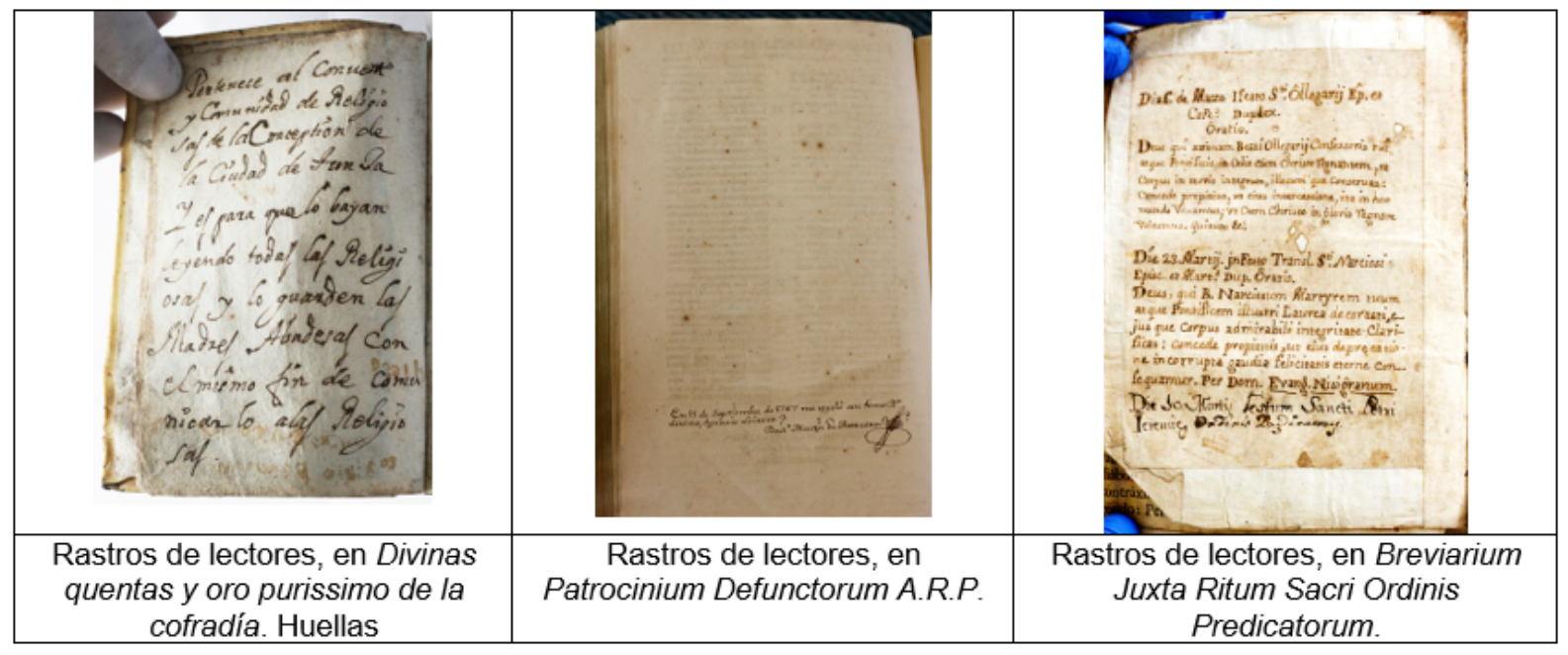

Fuente: elaboración propia.

Las huellas o rastros de los lectores en los libros antiguos también se dejaban mediante la inserción de grabados (ver figura 13). 
FIGURA 13

Rastros de lectores mediante grabado en los libros antiguos.

\begin{tabular}{|l|l|l|}
\hline & \\
\hline & & \\
\hline
\end{tabular}

Fuente: elaboración propia.

En la investigación, también fue posible determinar la existencia de categorías en los libros antiguos de la Colección que se propusieron para identificarlos, establecer el corpus y analizar los objetos culturales gráfica e históricamente, como las marcas de agua y los tipos de tapas (ver figura 14).

FIGURA 14

Otras características de los libros presentes en los libros antiguos de la colección.

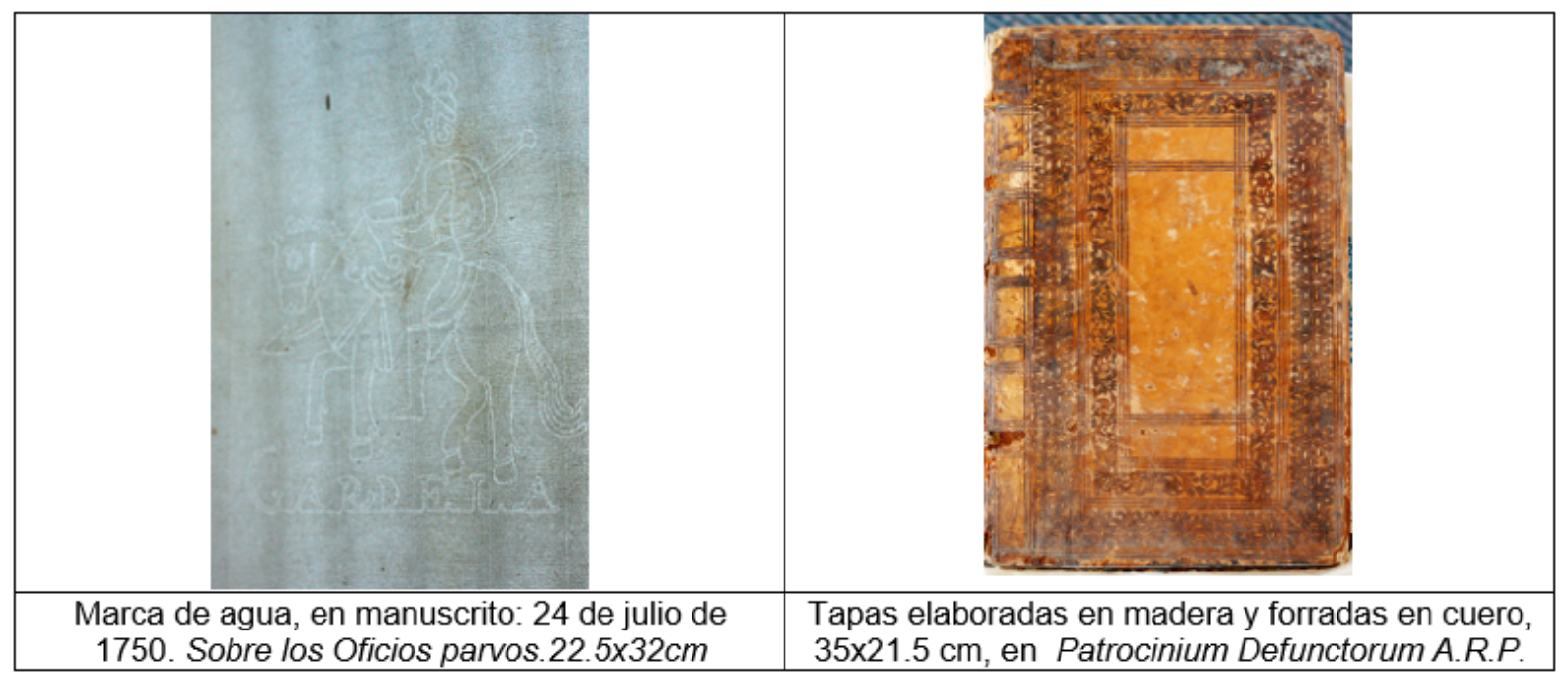

Fuente: elaboración propia.

Así como el manejo de dos tintas, pese a la predominancia del uso de una sola tinta, en las portadas y el contenido de los libros antiguos de la colección (ver figura 15). 
FIGURA 15

Manejo de tintas en los libros antiguos.

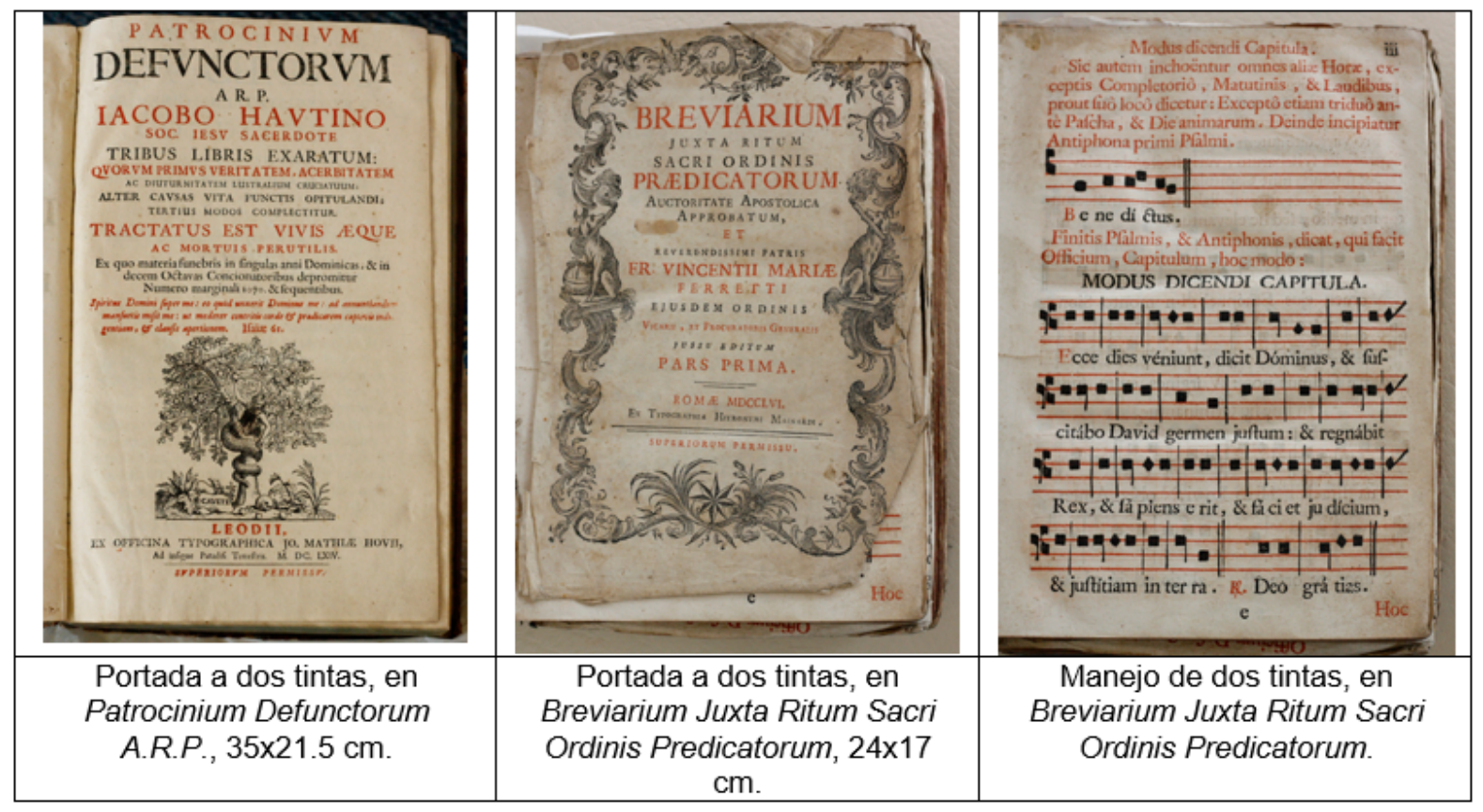

Fuente: elaboración propia.

\section{Conclusiones}

El estudio gráfico e histórico de los libros antiguos de la Colección de la Orden de predicadores de la Biblioteca del Convento de Santo Domingo Guzmán permitió constatar la riqueza visual y patrimonial de los mismos, tan importantes no solo para la historia del libro, sino también para la historia del diseño gráfico en Colombia y del país, en general.

Sin embargo, la investigación permitió establecer, pese a la importancia de la colección, la existencia de condiciones de deterioro ocasionadas por su ubicación en un espacio que no permite la adecuada conservación de los libros. Esta situación debe mejorar implementado condiciones lumínicas, de ventilación y de mantenimiento permanente.

Los 52 libros de la colección, determinados en la etapa descriptiva y de establecimiento del corpus de la investigación y analizados de acuerdo con las categorías objetuales y de contenido del libro antiguo, presentan una gran variedad de materiales y formatos. Entre ellos se pueden localizar libros de formatos más pequeños, $7 \times 10 \mathrm{~cm}$, como el Novenario y Facil Methodo para celebrar las Festividades de la Virgen Maria Nuestra Señora, así como también de mayor tamaño, 38x 25.5, como un libro que no tenía portada ni título (número 47 del corpus), cuyo contenido hace referencia a la vida y sacrificios de los santos.

En cuanto al análisis de las portadas y las tintas empleadas, se pudo determinar que, aunque la mayoría de los libros están impresos a una sola tinta, hay libros en dos tintas: roja y negra. Las encuadernaciones son variadas, de forma predominante se destaca en pergamino, aunque también se hallan en madera forrada en piel o tela o con cierres laterales en cuero o en metal.

En términos generales se obtuvieron los siguientes resultados: 16 libros impresos a dos tintas (roja y negra), 30 libros en una sola tinta (negra), 6 manuscritos, 33 libros con encuadernaciones en pergamino, 1 libro con encuadernación de madera cubierta de tela, 16 libros con encuadernaciones de madera y cuero, 2 libros sin encuadernación y 2 libros con inserciones. 
Con respecto al análisis de las características editoriales, el estudio arrojó que la mayoría de los libros están publicados en latín y algunos en castellano; así como que todos cumplen con las autorizaciones y privilegios otorgadas por las autoridades correspondientes. Uno de los resultados más curiosos de este aspecto fue descubrir la existencia de varios libros de la comunidad religiosa de los jesuitas, lo que puede deberse a las expulsiones de las que fueron objeto en 1767, de la que regresaron en 1855, y la de 1863, que hicieron que sus libros se desperdigaran y fueran adquiridos por otras órdenes religiosas o por coleccionistas particulares.

En cuanto al análisis de las formas tipográficas, en los libros antiguos de esta colección, son frecuentes los tipos romanos, cursivos, las capitulares xilográficas con elementos ornamentales, algunas formas tipográficas góticas, y demás elementos ornamentales que facilitaban la lectura y la finalización de capítulos. Fue interesante descubrir cómo, en algunas de las obras analizadas, las formas tipográficas eran imitadas a través de los trazos caligráficos, con lo cual se establece una estética visual y una identidad de los libros impresos, en relación con los manuscritos.

Es importante mencionar que el apartado dedicado al análisis tipográfico se viene adelantando en un capítulo particular dentro del proyecto.

Finalmente, la investigación hace un aporte al reconocimiento del valor patrimonial e histórico de los libros antiguos en Colombia, de sus espacios de circulación, de los elementos gráficos elaborados para composiciones muy variadas, de un solo cuerpo de texto hasta varias columnas dentro de una página, así como de los rastros de quienes los tuvieron entre sus manos, a la luz de una vela en la época, en lo público o en lo privado.

Los libros antiguos de la colección son documentos que reflejan una época de la historia del país y de una comunidad religiosa, a partir de cuyo estudio se puede comprender el impacto de la producción bibliográfica en los procesos educativos e intelectuales del país.

\section{REFERENCIAS}

Bedoya, G. (2011). La prensa como objeto de investigación para un estudio histórico de la literatura colombiana: balance historiográfico y establecimiento del corpus. Estudio de literatura colombiana, 28, 89-109.

Burke, P. (2002). Historia social del conocimiento. Barcelona: Paidós.

Chartier, R. (1996). El orden de los libros: lectores, autores, bibliotecas en Europa entre los siglos XIV y XVIII. Barcelona: Gedisa.

Darnton, R. (1982). What is the history of books? Daedalus, $111(3), 65-83$.

García, I. (2011). Secretos del estante: elementos para la descripción bibliográfica del libro antiguo. México: Universidad Autónoma de México.

García, I. (2018). Ideas navegantes: cajones de libros para los dominicos novohispanos: los dominicos en la educación, siglos XVI-XXI. Bogotá: Universidad Santo Tomás.

García, M. R. (2015). Bibliotecas de la Nueva Granada del siglo XVII: la biblioteça de Fray Cristóbal de Torres en el Colegio Mayor de Nuestra Señora del Rosario. Historia y memoria, 11, 17-55. Recuperado de http://www.scie lo.org.co/pdf/hismo/n11/n11a02.pdf

Guarín, Ó. (2011). La imprenta y su desarrollo en la Nueva Granada y Colombia. Huellas digitales: colecciones digitales de la Biblioteca Nacional. Recuperado de https://www.academia.edu/988577/La_imprenta_y_su_desarrollo_e n_la_Nueva_Granada_y_Colombia

Melo, J. O. (2004). La libertad de prensa en Colombia: su pasado y sus perspectivas actuales. Recuperado de https://www.banrepcultural.org/exposiciones/un-papel-toda-prueba/la-libertad-de-prensa-en-colombia-supasado-y-sus-perspectivas

Melo, J. A. (2020). Clemencia y obediencia: el vínculo amoroso entre el rey y los vasallos del Nuevo Reino de Granada entre 1780 y 1800 . Historia critica, 78, 25-43. 
Plata, W. (2015). Los dominicos, la tercera orden y un orden social: Santafé de Bogotá, siglos XVI-XIX. Historia y sociedad, 28, 79-119. https://doi.org/10.15446/hys.n28.47965

Plata, W. (2016). Frailes y evangelización en el Nuevo Reino de Granada (s. XVI): vicisitudes de un proceso conflictivo y no muy exitoso. Franciscanum, 165(58), 263-302.

Rubio, A. (2013). Bibliotecas particulares en la Nueva Granada: presencia y significado del libro religioso. Anuario colombiano de historia social y de la cultura, 2(40), 27-47.

Rubio, A. (2017a). Los inicios de la tipografía neogranadina, 1738-1782: letras y cajistas hacia un lenguaje impreso. Lingüistica y literatura, 38, 55-68.

Rubio, A. (2017b). Prácticas y actores del comercio de libros en la Nueva Granada. Historia (São Paulo), 31 (36). ht tps://doi.org/10.1590/1980-436920170000000031

Rubio, A. y Murillo, J. (2017). Historia de la edición en Colombia, 1738-1851. Bogotá: Instituto Caro y Cuervo.

Rueda, O. y López, J-U. (2014). Convento de Santo Domingo de Tunja: proyecto comunitario de 2014. Tunja: Frailes de la Orden de Predicadores.

Sierra, A. (2009). La censura de libros y papeles en España y los indices y catálogos españoles de los probibidos y expurgados. Madrid: Cuerpo Facultativo de Archiveros, Bibliotecarios y Arqueólogos.

Universidad Santo Tomás. (2011). 15 años de presencia en Tunja, 1996-2011. Tunja: USTA. 